\title{
O corpo expropriado: Bernardo Kucinski - Diário de uma perda
}

\author{
The Expropriated Body: Bernardo Kucinski - Diary of a Loss \\ El cuerpo expropiado: Bernardo Kucinski - Diario de una perdida \\ Ettore Finazzi-Agrò
}

\section{Resumo}

A tarefa "impossível" que parte da literatura brasileira mais recente tem atribuído a si mesma pode ser resumida na vontade de testemunhar, através da escrita, as feridas e as marcas sangrentas que a ditadura militar deixou atrás de si e que o novo regime autoritário tenta novamente apagar, repetindo o gesto de rasura do passado aviado pela Lei da Anistia. Nesse contexto de "exceção", no qual o poder instituído tenta impor uma nova (e, todavia, já tragicamente experimentada) ordem discursiva, a literatura desenvolve um papel fundamental, colocando-se numa posição periférica, num espaço-tempo ainda “excepcional" que lhe permite dar voz e corpo às vítimas. Para exemplificar essa tentativa de recuperação da memória pessoal e coletiva, este artigo analisa as obras de Bernardo Kucinski, detendo-se, em particular, em Os visitantes.

Palavras-chave: Bernardo Kucinski, K.: relato de uma busca, Os visitantes, pós-verdade.

\begin{abstract}
The "impossible" task that part of the most recent Brazilian literature has assigned itself can be summarized in the desire to witness, through writing, the wounds and bloody marks that the military dictatorship left behind and which the new authoritarian regime attempts yet again to erase, repeating the past erasure gesture enacted by the Amnesty Law. In this context of "exception," in which institutional power tries to impose a new (and yet tragically experienced) discursive order, literature plays a fundamental role, placing itself in a peripheral position, in an "exceptional" space-time in order to give voice and flesh to the victims of the past. To exemplify this attempt to recover personal and collective memory, this article analyzes the works of Bernardo Kucinski, focusing in particular on Os visitantes.
\end{abstract}

Keywords: Bernardo Kucinski, K.: relato de uma busca, Os visitantes, post-truth.

\begin{abstract}
Resumen
La tarea "imposible" que una parte de la más reciente literatura brasileña se ha asignado a sí misma se puede resumir en el deseo de testimoniar, a través de la escritura, las heridas y las marcas sangrientas que la dictadura militar ha dejado atrás y que el nuevo régimen autoritario intenta borrar nuevamente, repitiendo el gesto de abolición de la culpa inaugurado por la Ley de Amnistía. En este contexto de "excepción", en el que el Poder trata de imponer un nuevo orden discursivo (pero ya experimentado de forma trágica), la literatura desarrolla un papel fundamental, situándose en una posición periférica, en un espacio-tiempo también "excepcional" que permite dar voz y carne a las víctimas. Para ejemplificar este intento de recuperar la memoria personal y colectiva, mi texto analizará las obras de Bernardo Kucinski, enfocándose en particular en Os visitantes.
\end{abstract}

Palabras-clave: Bernardo Kucinski, K.: relato de uma busca, Os visitantes, post-verdad.

Hoje, com medo e nojo, devemos mais uma vez mexer na água pútrida da repressão e da privação violenta da liberdade de opinião. Hoje, mais uma vez, é mister afundar as mãos na acqua toffana ${ }^{1}$ que envenenou e continua envenenando a vida de um povo, na sua maioria, sem culpa, de um país desprivado dos seus direitos - também daquele direito ao grito reivindicado,

\footnotetext{
*Universidade de Roma “La Sapienza”, Roma, Itália. Dorcid.org/0000-0001-5589-6375. E-mail: finazzi@uniroma1.it

${ }^{1}$ Come se vê, tomo aqui emprestado o título de um famoso livro de Patrícia Melo (1994).
} 
em 1977, por Clarice Lispector para a sua Macabéa (Lispector, 1999). Aquilo que resta, de fato, é apenas a possibilidade de denunciar com força esse estado de coisas, denúncia que muitas vezes passa sem passar - ou passando de forma enviesada ou alegórica, como no caso da Hora da estrela e em tantos outros - pela literatura: espaço incompressível de liberdade, água clara e corrente que qualquer ditadura, em todas as latitudes e em toda situação histórica, não consegue poluir ou segurar de todo.

Nessa perspectiva, a partir da representação ficcional duma situação de degradação humana e de opressão política, podemos às vezes reconstruir todo um contexto social e humano em que o estado de emergência ou de exceção é a regra, conforme nos indicou Walter Benjamin em suas Teses de filosofia da história (Benjamin, 1962). ${ }^{2}$ Uma condição, então, na qual o homem é tomado fora da lei (ex-ceptum, "excetuado", enquanto, por paradoxo, eximius, ou seja, "posto de lado"), para que a lei preserve a sua força, que neste caso é apenas força sem direito, manifestando-se, em suma, só como punição ilegítima e como repressão (Derrida, 1994).

A violência do poder - meio pelo qual se exprimem, em nível subjetivo, tanto o rancor e o ressentimento quanto o desejo de vingança - leva, nesse sentido, a uma situação de sequestro e, no limite, de extinção dos corpos. De fato, se, por um lado, o dispositivo biopolítico prevê um domínio absoluto sobre a vida nua dos indivíduos, é, por outro lado, evidente que aquele regime de regulação das existências individuais pode conduzir - e muitas vezes conduz - a uma verdadeira tanatologia, chegando, enfim, a uma expropriação sem retorno dos corpos. O corpo, ou melhor, o uso dele (analisado exemplarmente por Giorgio Agamben), no seu ser submetido a um poder absoluto, é exposto a uma potência que é aquela condensada, no direito romano, na fórmula vitae necisque potestas, ou seja, no poder de vida e de morte (Agamben, 2014).

Existem, todavia, casos que ultrapassam a oikonomia dos corpos e que são frequentes sobretudo a partir dos anos 1970. Visto que encontraram a sua realização mais contundente e trágica nos regimes ditatoriais latino-americanos, eles acabaram sendo definidos por uma palavra que é idêntica em espanhol e em português, generalizando-se, depois, em nível mundial: refiro-me, evidentemente, ao caso dos desaparecidos. De fato, quem desaparece não é apenas usado e abusado pelo poder até a morte, mas seu corpo é sequestrado e some no nada. No interior desse dispositivo tanatológico, o sujeito oprimido e reprimido não é tanto a vítima, mas também quem sobrevive, ou, para utilizar os termos de Primo Levi (Levi, 1986), não é o submerso (a quem foi negado, sem culpa, o direito de viver), mas, por paradoxo, aquele que, em aparência, é o salvado, quem - também sem culpa - busca obstinadamente a verdade sobre o sumiço da pessoa amada e não a encontra. Esse território baldio e angustiante que segue o evento traumático da perda é aquele onde, num silêncio ensurdecedor, moveram-se e continuam movendo-se os sobreviventes e os parentes das vítimas - Las Madres de Plaza de Mayo, por exemplo, assim como K., pai e sogro de desaparecidos e protagonista do romance de Bernardo Kucinski (2016a).

É fácil, obviamente, distinguir os dois casos, visto que as primeiras atuam na realidade e aparecem nas crônicas argentinas e internacionais dos últimos quarenta anos, enquanto K., embora real, é apenas o pai de um escritor brasileiro que tentou, em 2014, contar a história romanceada da busca inconcludente, por parte do pai, da filha desaparecida. Muitos viram, evidentemente, na escolha do título uma referência a Kafka e, de fato, o subtexto do romance tem muito a ver nem tanto com $O$ Processo quanto com $O$ Castelo do grande escritor de Praga. Mas, em vez de tentar encontrar as semelhanças ideológicas e de conteúdo entre $K$. e a narrativa de Kafka, o que é necessário ainda investigar é o modo como a literatura testemunha e representa a privação de instâncias básicas como o direito de viver e morrer, a questão dos direitos individuais, enfim, a impotência do homem diante da lei (e uso, mais uma vez, uma expressão kafkiana). Emoldurado num contexto literário, a busca de K. cessa de ser apenas um

\footnotetext{
${ }^{2}$ Trata-se da oitava tese, sobejamente conhecida, que na tradução portuguesa começa assim: "A tradição dos oprimidos nos ensina que o 'estado de exceção' em que vivemos é na verdade a regra geral. Precisamos construir um conceito de história que corresponda a essa verdade. Nesse momento, perceberemos que nossa tarefa é originar um verdadeiro estado de exceção; com isso, nossa posição ficará mais forte na luta contra o fascismo". Note-se que, na primeira tradução italiana para a qual eu remeto na bibliografia, em vez de exceção, a palavra utilizada é emergenza ("emergência").
} 
relato (como indica o subtítulo) para se transformar numa grande parábola da procura pela palavra ausente e do ausente, pela palavra-chave que permitiria penetrar no castelo ou dar conta, de modo integral, da falência de toda busca por uma verdade apagada e impossível de ser recuperada - como, aliás, o corpo e a voz (ou o grito) das vítimas. ${ }^{3}$

Nessa perspectiva, mais que o dramático fracasso da busca do pai, seria conveniente falar do aparente fracasso do filho em busca da palavra adequada para representar a verdade da violência e da repressão, ou seja, falar hoje de Os visitantes (Kucinski, 2016b), em vez de analisar a forma e os conteúdos de K., embora os dois textos sejam, evidentemente, fortemente entrançados e consequenciais. Publicada cinco anos depois de K., a "novela" (como é definido Os visitantes pelo seu subtítulo), apresenta-se, de fato, como um suplemento necessário ao romance. Desta vez, porém, o protagonista não é o pai, mas o filho, isto é, o próprio Bernardo Kucinski que se interroga e é interrogado sobre o valor e os limites da sua obra anterior.

Desde o início, com efeito, o autor lamenta o silêncio que rodeia o seu romance, supondo quase uma espécie de censura em relação ao livro escrito por ele. Esse silêncio público, todavia, é preenchido, em nível privado, pelas intervenções sucessivas de pessoas que visitam o autor, todas lamentando erros, omissões ou acréscimos em relação à verdade do acontecido. Esta multidão de visitantes - que podemos também considerar uma espécie de voz da consciência, ou melhor, da má consciência de Bernardo Kucinski a respeito do seu modo de contar a história do pai e sua busca pela filha - representa algo mais na economia da procura dos corpos ausentes: os visitantes são os representantes e os porta-vozes emblemáticos de uma impossibilidade de restituir por completo uma verdade que foi apagada pelo poder e que também a literatura consegue representar só de forma imperfeita. Isto porque a realidade da repressão e da violência pretende um mergulho total na despersonalização e, no limite, no sumiço do corpo, efeitos extremos que proíbem qualquer linguagem. Por isso, de fato, os afogados precisam sempre de um sobrevivente que tome a palavra em nome e por conta da vítima, sem conseguir ocupar, todavia, o lugar da "testemunha integral", na definição de Agamben sugerida, mais uma vez, por Primo Levi (Agamben, 1998, p. 53-55 e ss.).

Os personagens que visitam Bernardo Kucinski são, nesse sentido, os emblemas de uma reconstrução impossível ou, pelo menos, sempre subjetiva e parcial daquilo que aconteceu. Desde a mulher que sobreviveu ao campo de concentração, até os companheiros de luta da irmã e do cunhado, e até aqueles que compartilharam com eles a prisão e a tortura, todos reivindicam a sua própria verdade, cada um trazendo uma parcela do seu vivido, criticando a versão do escritor, que se defende retrucando sempre que o seu $K$. não é nem nunca quis ser uma crônica fiel, mas apenas uma reconstrução pessoal e ficcional dos fatos. De resto, o autor tinha declarado na abertura do seu "relato de uma busca": "tudo neste livro é invenção, mas quase tudo aconteceu" (Kucisnki, 2016a, p. 11). Esta frase remete, mais uma vez, para a relação entre história e ficção e para o potencial de denúncia que a literatura encerra, sem abrir mão do seu caráter hipotético.

Os visitantes apresenta, nesse sentido, uma longa teoria de revenants, de fantasmas de uma história a ser sem fim recontada, mas que nunca atinge a verdade definitiva: como a busca do pai em K., também o passado relembrado ou reivindicado pelos que passam pelo apartamento de Kucinski é um território baldio, onde os protagonistas tentam afirmar cada um o seu ponto de vista sobre o acontecido, sem todavia chegar a nos devolver um quadro exato daquilo que eles viveram e que, com e através deles, o país inteiro viveu. O livro, mais uma vez, oferece uma versão que gira em falso, testemunhando com isso a impossibilidade de curar uma ferida purulenta que continua - até hoje - a sangrar. O livro é, nesse sentido, um testemunho de muitas vozes, mas que, todavia, fica nos arredores de uma verdade única, na periferia de uma história trágica habitada apenas pelo poder soberano, pela injustiça e pela violência dos seus agentes.

Podemos então considerar Os visitantes um doloroso remate, uma espécie de post scriptum que, repercorrendo a trajetória do texto escrito anteriormente e indo além do "post scriptum" que

\footnotetext{
${ }^{3}$ Para uma revisão mais completa da produção narrativa de Bernardo Kucinski (e, mais em geral, da literatura sobre a memória da ditadura), ver Figueiredo (2017, p. 125-144). Sobre K., em particular, ver ainda Scaramucci (2016/2017) e Russo (2017, p. 35-46).
} 
fecha K. (Kucinski, 2016a, p. 168), não chega a desatar os nós de um desaparecimento que continua acontecendo, de novo e de novo, sem ter um fim; que não encontra, de fato, uma conclusão lógica - ou seja, também uma palavra decisiva. É justamente essa natureza fatalmente póstuma, em tempos de pós-verdade, que faz desse livro uma obra significativa, tanto na forma quanto no conteúdo. Na forma, porque a procura da verdade é a demanda plural e dispersa desse lógos que se sabe, desde o início, que não pode ser encontrado; no conteúdo, porque os vultos e as vozes dos sobreviventes carregam cada um e cada uma as cicatrizes e os ecos de uma experiência trágica - aquela experiência que, de modo mais explícito (mas sem abrir mão de um registro irônico que vai voltar em Os visitantes, como veremos a seguir), Bernardo Kucinski tinha ilustrado nos contos coligidos em Você vai voltar pra mim e outros contos (Kucinski, 2014).

Em tempos como os atuais, de exaltação do golpe, do AI-5 e dos torturadores, é bom reatar os fios da lembrança, recuperar a memória censurada de lutos e perdas. Obviamente, a distância temporal a respeito da ditadura pretende um afastamento ao contrário em relação aos fatos - e esse modo de se afastar se aproximando do que realmente aconteceu leva a uma situação paradoxal, que, com efeito, torna-se evidente quase até o fim em Os visitantes. Sendo, com efeito, uma espécie de metatexto ou de paratexto em relação a $K$. (visto que fica, ao mesmo tempo, fora e dentro dele e o complementa), esse segundo livro, relatando, mais uma vez, uma busca, acaba por assumir um tom irônico, que pode ser mais bem definido quando aproximado ao típico humor judaico, isto é, ao humor de um povo milenarmente oprimido. As acusações indignadas que Kucinski recebe de seus visitantes, de fato, tornam-se grotescas por não levar em conta o caráter novelesco do livro anterior, mas, ao mesmo tempo, são acusações autoirônicas que o escritor, à procura da fama e maravilhado pelo silêncio em volta da obra, move a si próprio enquanto autor de $K$. - livro escrito, aliás, sem ter noção exata daquilo que realmente aconteceu (ele é acusado, por um dos visitantes, de ter vivido no exterior durante a captura e o desaparecimento da irmã) e sem se aperceber da dor que uma reconstrução, embora ficcional, do passado pode provocar nos leitores.

Esse registro irônico e autoirônico parece prevalecer até o último capítulo do livro, intitulado significativamente de "Post mortem" e datado dois anos depois das visitas das testemunhas, daqueles que lamentam as imprecisões e as falhas contidas em K.: relato de uma busca (Kucinski, 2016b). Dois anos de perdas e desenganos, visto que um dos visitantes, no entanto, morreu, e outros ficaram decepcionados com os resultados da Comissão da Verdade - que, de resto, nada apurou sobre o desaparecimento da irmã e do cunhado de Bernardo Kucinski. A verdade, então, parece sepultada para sempre (embora resulte quase grotesco falar em sepulcros para corpos que nunca foram encontrados) e o próprio autor declara ter "esquecido da novela e de tudo" (Kucinski, 2016b, p. 76) quando recebe uma ligação inesperada por parte do âncora de um programa televisivo que o alerta sobre uma entrevista de um agente da repressão que vai passar naquela noite. Kucinski espera, enfim, a revelação daquilo que realmente aconteceu com a irmã, visto que o torturador estava envolvido no assassinato e fez desaparecer seu corpo. Estamos, de fato, na época - que dura, lamentavelmente, até hoje - em que os carrascos não só são entrevistados sobre seus crimes, mas se vangloriam deles e são, ainda por cima, elogiados pelo poder atual como heroicos agentes da luta contra o comunismo.

A entrevista do torturador revela, com datas e nomes, aqueles que participaram dessa prática bárbara, mencionando o uso de incinerar os corpos dos que morriam à bala ou por causa da tortura e lembrando que entre aqueles que foram jogados no forno estavam também a irmã e o cunhado de Bernardo Kucinski. Estaríamos, enfim, diante da verdade: a busca do pai poderia se considerar finalmente concluída, apesar do sumiço definitivo dos corpos, sancionado pelo entrevistado. E é trágico pensar que o método para apagar qualquer rastro das vítimas seja o mesmo utilizado nos campos de concentração: para uma família judaica, este é um ultraje a mais, remetendo, aliás, para o testemunho dramático da primeira visitante, uma velha mulher sobrevivente de Auschwitz. O casal - ou melhor, o corpo deles - teria sido, de fato, vítima de uma prática comum nos campos: vítima póstuma e, por assim dizer, complementar (e, por isso, mais uma vez "excetuada" e "exímia" no sentido latino acima indicado de "posta de lado", deslocada no tempo e no espaço) da Shoah. 
Só que, depois da confissão desse agente da repressão, um procurador de justiça é entrevistado e nega a credibilidade do depoimento do réu confesso, com a acusação de que ele está tentando se salvar graças à Lei de Anistia. A conclusão aporética do juiz é esta:

Entendemos que enquanto não se encontrar o corpo de um desaparecido trata-se de crime continuado de sequestro, portanto fora do âmbito da Lei de Anistia; ora se tomarmos como verdade que os corpos foram cremados, deixa de ser crime continuado e os criminosos se safam, ganham a imunidade da Lei de Anistia (Kucinski, 2016b, p. 82).

A verdade, então, é considerada, na tortuosa lógica jurídica, apenas um truque para fugir à pena. Kucinski e sua ex-mulher sabem, porém, que o depoimento do agente é fidedigno e ficam de mãos dadas contemplando mudos e estarrecidos mais esta denegação da verdade. E assim o livro se conclui:

Um truque. O jovem procurador disse que é truque, que é mentira, que não aconteceu, que os corpos não foram incinerados num forno de assar melaço. Eu e minha ex sabíamos que era verdade. Sempre soubemos (Kucinski, 2016b, p. 83).

Saber a verdade não significa, então, que ela possa ser aceita e divulgada como tal, porque diante da lei (para voltar a Kafka) o sujeito é impotente, ou seja, não consegue que a lei reconheça aquilo que se apresenta ou que ele identifica como verdadeiro. O que é e foi pode ser considerado como algo que não é nem nunca foi, ou que pode não ser ou ter sido daquele jeito porque o processo jurídico procede por suspeitas, interrogações e dúvidas, resumindo-se na conhecida fórmula in dubio, pro reo. No caso: visto que os corpos não foram encontrados - nem nunca o serão, tendo sido, de fato, cremados -, o réu confesso não pode ser condenado pelos crimes que ele próprio admite, de forma circunstanciada, ter cometido, porque o detentor da lei considera sua admissão de culpa uma mentira.

$O$ relato de uma busca, iniciado em $K$. e complementado em Os visitantes, não pode, de fato, chegar a uma conclusão oficial, visto que o que aconteceu é, sim, reconhecido como autêntico pelos familiares, mas, todavia, negado pelo poder. Conclusão trágica ou imbuída de ironia trágica pela qual saber a verdade não exclui a obrigação de procurar, ainda e sempre, $o$ reconhecimento da verdade. Esse é, no fundo, o drama dos sobreviventes que não possuem um corpo que possa ser mostrado, chorado e sacralizado no luto: a questão do uso dos corpos, no caso dos desaparecidos, é ultrapassada pela ausência deles - não mais visitantes ou revenants, visto que não podem mais voltar, permanecendo, cada dia mais diáfanos, só na memória sem resgate dos que ficam.

O agente da repressão e o procurador de justiça podem ser considerados, nesse sentido, os últimos visitantes, sendo aqueles depois dos quais não pode haver mais visitas: com eles, de fato, a verdade some de vez como sumiram, para nunca mais voltar, os desaparecidos. Por isso, justamente, o título do capítulo final é altamente significativo, porque aquilo que vem depois da morte, depois do uso e abuso do corpo, não é a recuperação e a redenção da verdade, mas a condenação a uma procura infinita e sem perspectivas, guardando em si mesma o seu alvo e o seu significado. O título "Post mortem", fechando um livro que, como apontei, é uma espécie de post scriptum ao livro anterior, aponta, de fato, para uma conclusão inconcludente, visto que os últimos visitantes decretam o fim da busca e da viagem rumo à verdade no mesmo gesto com que ela é exposta e revelada, ratificando a ausência do crime assim como da materialidade do corpo machucado, matado e cremado.

Num período histórico dominado pela pós-verdade - isto é, por uma verdade que se apresenta como uma simplificação aparentemente ingênua dos fatos, sendo, por contra, uma distorção tendenciosa de acontecimentos reais -, o livro de Bernardo Kucinski mostra dramaticamente como não apenas sua irmã e seu cunhado, mas o país inteiro talvez esteja obrigado a viver num depois, em que também a morte dos opositores políticos é considerada como celebração duma verdade censurada e impossível de ser recuperada. Nesse pós-tudo, nesse vazio de valores humanos em que vivemos a única opção, enfim, é continuar lutando pelo reconhecimento dos direitos individuais, é continuar buscando aquilo que o próprio ato de buscar proíbe de atingir, afastando o objeto da procura para além de qualquer capacidade 
humana de entender os mecanismos do poder - um poder que se esconde e se revela só dentro de uma aporia, ou seja, só dentro de um castelo com todas as portas trancadas.

\section{Referências}

AGAMBEN, Giorgio (1998). Quel che resta di Auschwitz: l'archivio e il testimone - Homo sacer III. Torino: Bollati Boringhieri.

AGAMBEN, Giorgio (2014). L'uso dei corpi. Homo sacer IV/2. Vicenza: Neri Pozza.

DERRIDA, Jacques (1994). Force de loi: le "fondement mystique de l'autorité". Paris: Galilée.

FIGUEIREDO, Eurídice (2017). A literatura como arquivo da ditadura brasileira. Rio de Janeiro: 7Letras.

KUCINSKI, Bernardo (2014). Você vai voltar pra mim e outros contos. São Paulo: Cosac Naify.

KUCINSKI, Bernardo (2016a). K.: relato de uma busca. São Paulo: Companhia das Letras.

KUCINSKI, Bernardo (2016b). Os visitantes: novela. São Paulo: Companhia das Letras.

LEVI, Primo (1986). I sommersi e i salvati. Torino: Einaudi.

LISPECTOR, Clarice (1999). A hora da estrela. 24. ed. Rio de Janeiro: Rocco.

MELO, Patrícia (1994). Acqua toffana. São Paulo: Companhia das Letras.

RUSSO, Vincenzo (2017). Pater, pátria e a memória como patrimônio: sobre K.: relato de uma busca, de Bernardo Kucinski. Estudos de Literatura Brasileira Contemporânea, Brasília, n. 50, p. 35-46. jan./jun. Disponível em: https:/ / bit.ly/2JqS2NF. Acesso em: 27 set. 2019.

SCARAMUCCI, Marianna (2016/2017). K. Relato de uma busca di B. Kucinski e Não falei di B. Bracher: due narr(azioni) del trauma. Tese (Dottorato in Studi Linguistici, Letterari e Interculturali in Ambito Europeo ed Extra-europeo) - Università degli Studi di Milano, Milano. Disponível em: https://bit.ly/2JaOEGE. Acesso em: 27 set. 2019. 